\title{
Vaginal Carcinosarcoma
}

National Cancer Institute

\section{Source}

National Cancer Institute. Vaginal Carcinosarcoma. NCI Thesaurus. Code C40278.

An aggressive mixed epithelial and mesenchymal neoplasm that arises from the vagina

and is characterized by the presence of a malignant epithelial component and a

malignant mesenchymal component. 